\title{
AVALIAÇÃO DE CITRANDARINS E OUTROS HÍBRIDOS DE TRIFOLIATA COMO PORTA-ENXERTOS PARA CITROS EM SÃO PAULO ${ }^{1}$
}

\author{
SILVIA BLUMER ${ }^{2} \&$ JORGINO POMPEU JUNIOR ${ }^{3}$
}

\begin{abstract}
Resumo -Laranjeiras Valência enxertadas em citrandarins e outros híbridos de trifoliata foram plantadas em 1988, em Itirapina (SP), num Latossolo Vermelho-Amarelo textura arenosa e conduzidas sem irrigação. O citrandarin Sunki x English (1.628), sem diferir estatisticamente de Cleópatra x Rubidoux (1.660), Cleópatra x English (710), Cleópatra x Swingle (715) e do trangpur Cravo x Carrizo (717), induziu a maior produção de frutos nas cinco primeiras colheitas do experimento (1991-1995), sendo que os três primeiros foram os mais produtivos nas três últimas colheitas. Os citranges Troyer e Carrizo foram significativamente inferiores aos citrandarins Sunki x English (1.628), Cleópatra x Rubidoux (1.660) e Cleópatra x English (710) em todos os anos, exceto 1994. Nenhuma das plantas apresentou sintomas de suscetibilidade à tristeza ou ao declínio. Os seedlings dos portaenxertos diferiram quanto à área lesionada pela inoculação com Phytophthora parasitica. Os citrandarins Cleópatra x Swingle (1.587), Cleópatra x Trifoliata (1.574), Cleópatra x Rubidoux (1.600), Clementina x Trifoliata (1.615) e o limão Cravo x citrange Carrizo (717) foram significativamente mais resistentes que Cleópatra x Christian (712), Sunki x English (1.628), Cleópatra x Swingle (715) e Cleópatra x English (710).
\end{abstract}

Termos para indexação: porta-enxertos híbridos, citranges, híbridos de Sunki, híbridos de Cleópatra, Phytophthora.

\section{PERFORMANCE OF CITRANDARINS AND OTHERS TRIFOLIATE HYBRIDS ROOTSTOCKS IN SAO PAULO,} BRAZIL

\begin{abstract}
Valencia sweet orange trees budded onto citrandarins and others trifoliate hybrids rootstocks from the USDA Horticultural Research Laboratory, Fort Pierce, Florida, were planted in 1988 on a sandy textured Oxisol in São Paulo State, Brazil, and managed without irrigation. Tristeza and blight diseases are endemic in this area. Trees of Sunki x English (1.628), Cleopatra x Rubidoux (1.660), Cleopatra x English (710), Cleopatra $x$ Swingle (715) and Rangpur lime x Carrizo citrange (717), produced the highest cumulative yields in the first five crops (1991-1995). The first three rootstocks induced the highest crops in the last three years. Carrizo and Troyer citranges had the lowest productions in all years except in 1994. None of the trees showed symptoms of tristeza or blight diseases. Seedlings of these rootstocks were compared for resistance to Phytophthora parasitica inoculations. The citrandarins Cleopatra x Swingle (1.587), Cleopatra x Trifoliate (1.574), Cleopatra x Rubidoux (1.600), Clementine $\mathrm{x}$ Trifoliate (1.615) and Rangpur lime x Carrizo citrange (717), were significantly more resistant than the Cleopatra x Christian (712), Sunki x English (1.628), Cleopatra $x$ Swingle (715) and Cleopatra x English (710).
\end{abstract}

Index terms: Citranges, Sunki hybrids, Cleopatra hybrids, Phytophthora.

\section{INTRODUÇÃO}

Os citrandarins são híbridos de microtangerinas com Poncirus trifoliata e constituem uma nova geração de porta-enxertos a qual pretende reunir as vantagens apresentadas pelas tangerinas, como a menor suscetibilidade ao declínio; às dos trifoliatas, como a imunidade à tristeza e ao nematóide dos citros, grande resistência à gomose de Phytophthora e poder ananicante capaz de induzir a formação de plantas compactas e produtivas. Como as laranjeiras enxertadas nas tangerinas Cleópatra (C. reshni) e Sunki (C. sunki) e no trifoliata não são afetadas pela morte súbita dos citros, a expectativa é que pelo menos alguns dos citrandarins venham mostrar tolerância a essa doença. Como a irrigação é prática rotineira na maioria dos países citrícolas, a tolerância à seca não é um atributo exigido dos porta-enxertos, sendo este o principal limitante à adoção desses porta-enxertos em São Paulo.

Parte dos citrandarins produzidos pelo United States Horticultural Research Laboratory, Fort Pierce, Flórida, já foram avaliados em São Paulo. Os resultados mostraram que os mais promissores são Changsha x English small e Sunki x Benecke. Ambos são tolerantes à tristeza e ao declínio, e apresentam boa resistência à gomose de Phytophthora e ao nematóide dos citros. Induziram à laranjeira Valência produções de frutos 152 e $79 \%$ e de sólidos solúveis 176 e $105 \%$, respectivamente, maiores que as obtidas com o trifoliata Davis A (Pompeu Júnior et al., 2002a, b). O citrandarin Sunki x Benecke vem sendo recomendado na Flórida desde 2001 sob a sigla US-812.

Dentre as doenças que ocorrem em citros, a gomose de Phytophthora é considerada a principal doença fúngica dos portaenxertos de citros, tendo sido a causa da adoção e dos estudos de seleção de porta-enxertos. No Estado de São Paulo, a P. parasitica é a principal responsável pela perda de plantas em pomares e viveiros
(Feichtenberger, 2001).

Segundo Chiacchio \& Galli (1978), os danos causados por $P$. parasitica são mais prejudiciais às plantas que as de $P$. citrophthora por causarem lesões mais largas e atingirem maior número de elementos de vaso, ocasionando o anelamento do tronco e a morte da planta.

O uso de porta-enxertos resistentes é o método mais adequado na convivência com a doença, motivo pelo qual a determinação do grau de resistência de novos porta-enxertos constitui um dos critérios de seleção num programa de melhoramento.

Este artigo relata resultados da avaliação de citrandarins e outros híbridos de trifoliata, introduzidos pelo segundo autor no Centro APTACitros Sylvio Moreira, Cordeirópolis (SP), em 1982, em comparação com os citranges Troyer e Carrizo. Eles foram avaliados quanto as suas influências na produção de frutos da laranjeira Valência (C. sinensis) e resistência à gomose de Phytophthora parasitica.

\section{MATERIALEMÉTODOS}

Produção das plantas no período de 1991-1995

O experimento foi instalado em fevereiro de 1988, em Itirapina (SP), sob clima Cwa, num Latossolo Vermelho-Amarelo, textura arenosa, no espaçamento 7,5 m x 4,2 m e conduzido sem irrigação.

Foram comparados os seguintes porta-enxertos relacionados com seus números de registro no Banco Ativo de Germoplasma de Citros do Instituto Agronômico de Campinas: citranges (Citrus sinensis $x$ Poncirus trifoliata) Troyer (385) e Carrizo (387), citrandarins (C. reshni $x$ P. trifoliata) Cleópatra $\mathrm{x}$ English (710), Cleópatra $\mathrm{x}$ Christian (712), Cleópatra $x$ Swingle (715), (1.587) e (1.614), Cleópatra x Trifoliata (1.574), Cleópatra x Rubidoux (1.600) e (1.660), citrandarin (C. sunkix P. trifoliata) Sunki x English (1.628), citrentin (C. clementina x P. trifoliata) Clementina

\footnotetext{
${ }^{1}$ (Trabalho 018/2005). Recebido: 13/01/2005. Aceito para publicação 09/06/2005. Parte da Tese de Doutorado do primeiro autor apresentada à Esalq/USP. Suporte financeiro Fapesp.

${ }^{2}$ Eng. Agr. MSc. Doutoranda em Fitotecnia, Esalq/USP, Bolsista CAPES. e-mail: sblumer@esalq.usp.br.

${ }^{3}$ Eng. Agr. Dr. Pesquisador Científico VI, Centro APTA Citros Sylvio Moreira, Cordeirópolis (SP). Bolsista 1B CNPq.
}

Rev. Bras. Frutic., Jaboticabal - SP, v. 27, n. 2, p. 264-267, Agosto 2005 
$\mathrm{x}$ Trifoliata (1.615), e o trangpur [C. limonia $\mathrm{x}($ C. sinensis $x$ P. trifoliata $)]$ Cravo x Carrizo (717).

Como copa, foi utilizada a laranja-Valência clone nucelar, que, em meados da década de 1980, era a terceira copa da citricultura paulista, com cerca de $8 \%$ das plantas. Em 2002-2004, ela foi a copa mais importante, representando $38 \%$ das mudas presentes nos viveiros (Pompeu Junior, 2001; Pompeu Junior et al., 2004). Outro fator seletivo foi a ausência de relatos de incompatibilidade da cultivar com outros porta-enxertos, exceto limão Rugoso (C. jambhiri) (Bridges \& Youtsey, 1968).

Os porta-enxertos foram avaliados pelas produções anuais e total no período de 1991 a 1995. As plantas foram avaliadas, visualmente, quanto à manifestação de sintomas de intolerância à tristeza e ao declínio dos citros.

O delineamento estatístico foi em blocos ao acaso, com uma planta por parcela e dez repetições, num total de 130 plantas úteis. Para a comparação dos tratamentos, procedeu-se o teste de Tukey a 5\%.

\section{Resistência dos porta-enxertos à Phytophthora parasitica}

Para avaliar a resistência dos porta-enxertos à $P$. parasitica, seedlings com cerca de $20 \mathrm{~cm}$ de altura, foram inoculados com o isolado LRS 95/03 proveniente da Unidade de Pesquisa e Desenvolvimento de Sorocaba da APTA/SAA, selecionado pela maior agressividade dentre 10 isolados.

O experimento foi conduzido em sala com ambiente climatizado, com temperatura média de $26,3^{\circ} \mathrm{C}$ e umidade relativa do ar de $82 \%$, sendo as plantas mantidas sob iluminação artificial constante. $\mathrm{O}$ delineamento experimental foi o inteiramente casualizado, com 13 porta-enxertos e 10 repetições.

As folhas foram removidas até a altura de $15 \mathrm{~cm}$ do colo das plantas e a superfície do caule desinfetada com álcool 70\%. Para a inoculação, foi utilizada agulha previamente imergida em álcool $96^{\circ} \mathrm{GL}$ e flambada, cuja extremidade foi em seguida passada na borda da colônia, visando à aquisição de micélios do patógeno. A inoculação consistiu na perfuração da haste do seedling, a $10 \mathrm{~cm}$ de altura do colo, com a agulha infetada. A infecção por agulha foi utilizada, pois Siviero (2001) constatou ser um método eficiente na discriminação dos genótipos jovens com relação à resistência à $P$. parasitica.

A região da inoculação foi protegida com algodão envolvido por esparadrapo cirúrgico, de material livre de zinco, e umedecida diariamente com água destilada.

A avaliação das lesões foi efetuada decorridos 55 dias da inoculação, tendo sido coletados: comprimento e largura da lesão sob a casca, e diâmetro do porta-enxerto na altura da inoculação.

Como os tratamentos apresentavam diâmetros médios diferentes, decidiu-se compará-los pela porcentagem de área lesionada, ou seja, pela relação entre as áreas da lesão e do porta-enxerto expressa em porcentagem.

A área da lesão foi calculada utilizando a fórmula da área da elipse $(A=0,785 x$ comprimento $x$ largura $)$ e a área do porta-enxerto, na região da inoculação, utilizando-se da fórmula da área do retângulo, tendo como altura o valor constante de $1 \mathrm{~cm}$ (comprimento da maior lesão constatada em todos os porta-enxertos) e como largura o diâmetro do porta-enxerto. Para a análise estatística, utilizando Tukey, os dados foram transformados em arco-seno.

A porcentagem da área lesionada foi considerada mais representativa, que somente o comprimento ou a largura, ou ainda a área da lesão, tendo em vista que os porta-enxertos apresentam diâmetros diferentes.

\section{RESULTADOS E DISCUSSÃO}

\section{Produção das plantas no período de 1991-1995}

Na Tabela 1, são apresentadas as produções médias de frutos, em kg por planta, no período de 1991 a 1995.

Em 1991, primeiro ano de colheita, o citrandarin Cleópatra $\mathrm{x}$ Rubidoux (1.660) apresentou a maior produção, com 35,0 kg/pl, não diferindo estatisticamente dos porta-enxertos Cravo x Carrizo (717) e Cleópatra x English (710) com 30,2 e 26,8 kg/pl, configurando-os como os mais precoces.

Produções intermediárias foram obtidas com Sunki x English (1.628), com 21,6 kg/pl, Cleópatra x Swingle (715), com 19,4 kg/pl, Clementina x Trifoliata (1.615), com 19,2 kg/pl, Cleópatra x Rubidoux (1.600), com 15,5 kg/pl, Cleópatra x Swingle (1.614), com 11,0 kg/pl e Cleópatra x Swingle (1.587), com 8,0 kg/pl.

$\mathrm{O}$ citrandarin Cleópatra $\mathrm{x}$ Rubidoux (1.600) apresentou produção $56 \%$ menor que a de seu irmão-germano (1.660). O mesmo ocorreu com os citrandarins Cleópatra x Swingle (1.614) e (1.587) quando comparados com o homônimo (715). Neste caso, a redução da produção foi de 43 e $59 \%$, respectivamente.

As menores produções foram apresentadas pelos citrandarins Cleópatra x Trifoliata (1.574) e Cleópatra x Christian (712) e pelos citranges Troyer e Carrizo, que não diferiram entre si. Desses quatro porta-enxertos, somente a Cleópatra x Christian (712) mantinha as 10 plantas (repetições) estabelecidas no início do experimento. Os demais apresentavam parcelas (plantas) perdidas e suas médias se referem às plantas existentes.

Em 1992, o citrandarin Cleópatra x Swingle (715) apresentou a maior produção, com $71,8 \mathrm{~kg} / \mathrm{pl}$, não diferindo estatisticamente de Cleópatra x English (710), Sunki x English (1.628) e Cleópatra x Rubidoux (1.660) e superando em $24 \%$ a produção de seu homônimo (1.614).

TABELA 1 - Produção média, em número de frutos por planta, de laranjeiras-Valência enxertadas sobre híbridos de Poncirus trifoliata. Itirapina-SP.

\begin{tabular}{|c|c|c|c|c|c|c|}
\hline Porta-enxerto & 1991 & 1992 & 1993 & 1994 & 1995 & Média \\
\hline & \multicolumn{6}{|c|}{-------------------------------kg.planta ${ }^{-1}-------------------------$} \\
\hline Sunki x English 1.628 & $21,6 b-d$ & $68,1 \mathrm{ab}$ & $70,3 \mathrm{ab}$ & 70,2 a & 118,8 a & $69,8 \mathrm{a}$ \\
\hline Cleópatra x Rubidoux 1.660 & 35,0 a & $64,1 \mathrm{ab}$ & 75,7 a & 54,1 a-c & $97,2 \mathrm{ab}$ & $65,3 a$ \\
\hline Cleópatra x English 710 & $26,8 \mathrm{a}-\mathrm{c}$ & 70,6 a & $72,4 \mathrm{a}$ & $56,9 \mathrm{ab}$ & $97,8 \mathrm{ab}$ & $64,8 \mathrm{a}$ \\
\hline Cleópatra x Swingle 715 & 19,4 b-e & 71,8 a & 49,9 b-d & $30,2 \mathrm{~d}$ & 83,7 a-c & $51,0 \mathrm{ab}$ \\
\hline Cravo x Carrizo 717 & $30,2 a b$ & $52,4 \mathrm{bc}$ & 57,7 a-c & $44,9 b-d$ & $61,4 b-d$ & $49,3 \mathrm{ab}$ \\
\hline Cleópatra x Swingle 1.587 & 8,0 ef & $36,9 \mathrm{~cd}$ & $38,2 \mathrm{c}-\mathrm{f}$ & $40,7 b-d$ & $70,8 \mathrm{~b}-\mathrm{d}$ & $38,9 \mathrm{bc}$ \\
\hline Cleópatra x Swingle 1.614 & $11,0 \mathrm{~d}-\mathrm{f}$ & $54,3 \mathrm{a}-\mathrm{c}$ & $44,0 \mathrm{c}-\mathrm{e}$ & $25,3 \mathrm{~d}$ & $54,0 \mathrm{~cd}$ & $37,7 \mathrm{bc}$ \\
\hline Cleópatra x Rubidoux 1.600 & 15,5 c-e & $38,2 \mathrm{~cd}$ & $31,2 \mathrm{~d}-\mathrm{f}$ & $26,0 \mathrm{~d}$ & $60,7 b-d$ & $34,3 \mathrm{bc}$ \\
\hline Cleópatra x Trifoliata 1.574 & $3,0 \mathrm{f}$ & $24,0 \mathrm{de}$ & $33,8 \mathrm{~d}-\mathrm{f}$ & $35,9 \mathrm{~cd}$ & $55,5 \mathrm{~cd}$ & $30,4 \mathrm{bc}$ \\
\hline Clementina $\mathrm{x}$ Trifoliata 1.615 & $19,2 \mathrm{~b}-\mathrm{e}$ & $37,1 \mathrm{~cd}$ & 25,6 ef & $28,1 \mathrm{~d}$ & $36,4 \mathrm{~d}$ & $29,3 \mathrm{bc}$ \\
\hline Cleópatra x Christian 712 & $2,3 f$ & $26,2 \mathrm{de}$ & $31,9 \mathrm{~d}-\mathrm{f}$ & $26,7 \mathrm{~d}$ & $43,9 \mathrm{~cd}$ & $26,2 \mathrm{c}$ \\
\hline Citrange Troyer 385 & $2,5 f$ & $16,9 \mathrm{e}$ & $20,4 f$ & $40,9 b-d$ & $48,3 \mathrm{~cd}$ & $25,8 \mathrm{c}$ \\
\hline Citrange Carrizo 387 & $1,0 \mathrm{f}$ & $17,8 \mathrm{e}$ & 23,6 ef & $34,2 \mathrm{~cd}$ & $37,9 \mathrm{~d}$ & $22,9 \mathrm{c}$ \\
\hline DMS & 11,8 & 17,7 & 21,9 & 20,3 & 40,8 & 22,7 \\
\hline C.V.(\%) & 47,7 & 24,4 & 30,5 & 32,5 & 38,2 & 36,3 \\
\hline
\end{tabular}

*Médias seguidas pela mesma letra, na mesma coluna, não diferem entre si, pelo teste de Tukey, ao nível de $5 \%$ de probabilidade. 
Os citranges Troyer e Carrizo apresentaram as produções mais baixas: 16,9 e $17,8 \mathrm{~kg} / \mathrm{pl}$, não diferindo dos citrandarins Cleópatra $\mathrm{x}$ Trifoliata (1.574) e Cleópatra x Christian (712), respectivamente com 24,0 e $26,2 \mathrm{~kg}$ de frutos por planta.

Em 1993, os híbridos Cleópatra x Rubidoux (1.660), Cleópatra x English (710) e Sunki x English (1.628) apresentaram as maiores produções médias por planta, porém sem grandes ganhos de produção.

O citrandarin Cleópatra x Swingle (715), que apresentou a maior produção média em 1992, teve queda na produção de 30\% em 1993 e não diferiu estatisticamente de seus homônimos (1.614) e (1.587), os quais permaneceram com produção estável em relação a 1992.

Com exceção do trangpur Cravo x Carrizo, que apresentou produção média de $57,7 \mathrm{~kg} / \mathrm{pl}$, os demais porta-enxertos proporcionaram produções médias inferiores a $35 \mathrm{~kg} / \mathrm{pl}$, sendo que os citranges Troyer e Carrizo apresentaram as mais baixas produções.

Em 1994, o citrandarin Sunki x English (1.628) apresentou a maior produção média por planta $(70,2 \mathrm{~kg})$ e, desde 1992 , manteve constância de produção. Já Cleópatra x English (710) e Cleópatra x Rubidoux (1.660), apesar de não diferirem estatisticamente entre si e de Sunki x English (1.628), apresentaram redução na produção acima de $15 \mathrm{~kg} / \mathrm{pl}$ em relação a 1993. Neste ano, os destaques são os citranges Troyer e Carrizo, que praticamente dobraram a produção em relação aos anos anteriores.

Os citrandarins Cleópatra x Swingle (715) e (1.614), que, em 1992 e 1993, produziram, respectivamente, cerca de 60 e $50 \mathrm{~kg}$ de frutos por planta, apresentaram em 1994 redução na produção de quase $50 \%$.

Em 1995, Sunki x English (1.628) induziu a maior produção média de frutos por planta $(118,8 \mathrm{~kg})$, porém não diferiu estatisticamente de Cleópatra x English (710) e de Cleópatra x Rubidoux (1.660), que apresentaram produção média em torno de $97 \mathrm{~kg} / \mathrm{pl}$, o que representou aumento de $43 \%$ em relação a 1994, e de 30\%, em média, em relação a 1992 e 1993.

Os citrandarins Cleópatra x Swingle (715), (1.614) e (1.587) não diferiram entre si apesar dos ganhos de produção, dos dois primeiros, serem superiores a $100 \%$ e do terceiro ao redor de $40 \%$, quando comparados a 1994.

Em 1995, o Clementina x Trifoliata (1.615) e o citrange Carrizo induziram as menores produções, não diferindo estatisticamente do citrange Troyer e de Cleópatra x Christian (712).

No conjunto das cinco primeiras colheitas, os citrandarins Sunki x English (1.628), Cleópatra x Rubidoux (1.660), Cleópatra x English (710), Cleópatra x Swingle (715) e o trangpur Cravo x Carrizo (717) não diferiram estatisticamente entre si e induziram maior precocidade às laranjeiras-Valência, permitindo produções médias anuais superiores a $40,8 \mathrm{~kg}$ de frutos por planta. Eles foram estatisticamente mais produtivos que os citranges Troyer e Carrizo.

TABELA 2 - Porcentagem da área do porta-enxerto lesionada por inoculação com $P$. parasitica, utilizando o método da agulha infectada, decorridos 55 dias da inoculação.

Porta-enxerto

Cleópatra x English (710)

Cleópatra $x$ Swingle (715)

Sunki $x$ English (1.628)

Cleópatra x Christian (712)

Cleópatra $\mathrm{x}$ Swingle (1.614)

Citrange Carrizo (387)

Citrange Troyer (385)

Cleópatra x Rubidoux (1.660)

Clementina $x$ Trifoliata (1.615) Área lesionada $\%$

$47,4 \mathrm{a}^{*}$

$37,2 \mathrm{ab}$

$36,8 \mathrm{ab}$

$36,1 \mathrm{ab}$

$30,3 \mathrm{bc}$

$30,0 \mathrm{bcd}$

$27,2 \mathrm{bcd}$

$27,3 \mathrm{bcd}$

$19,7 \mathrm{~cd}$

$18,1 \mathrm{~cd}$

$18,1 \mathrm{~cd}$

Cleópatra x Rubidoux (1.600)

Cleópatra x Trifoliata (1.574)

Cleópatra $x$ Swingle (1.587)

DMS $=9,9 \quad$ C.V. $(\%)=20,6$

*Médias seguidas pela mesma letra não diferem entre si, pelo teste de Tukey, ao nível de $5 \%$ de probabilidade.
O citrandarin Cleópatra x Rubidoux (1.660) diferiu significativamente de seu homônimo (1.600), tendo produzido quase $100 \%$ mais que ele. Já os citrandarins Cleópatra x Swingle (715), (1.587) e (1.614) foram estatisticamente semelhantes, embora o primeiro tenha produzido cerca de $25 \%$ mais que os outros dois.

Resistência dos porta-enxertos à Phytophthora parasitica

$\mathrm{O}$ citrandarin Cleópatra $\mathrm{x}$ English (710) apresentou a maior porcentagem de área lesionada (47,4\%) pela infecção por $P$. parasítica, não diferindo dos citrandarins Cleópatra x Swingle (715), Sunki x English (1.628) e Cleópatra x Christian (712).

Os citranges Troyer e Carrizo apresentaram porcentagem de área lesionada de $27,2 \%$ e $30,0 \%$, respectivamente, diferindo estatisticamente apenas do Cleópatra x English (710).

Apesar de os citranges não terem diferido significativamente dos híbridos Clementina x Trifoliata (1.615), Cravo x Carrizo (717), Cleópatra x Rubidoux (1.600), Cleópatra x Trifoliata (1.574) e Cleópatra $x$ Swingle (1.587), eles apresentaram maior resistência ao patógeno.

Os dados revelam que descendentes de mesmos parentais apresentam reações diversas, o que pode ser visto pela comparação dos híbridos Cleópatra x Swingle (715), (1.614) e (1.587), sendo este significativamente menos danificado que seus irmãos. O mesmo não foi constatado nos descendentes de Cleópatra x Rubidoux e entre os citranges Troyer e Carrizo, ambos descendentes de laranja Washington navel (C. sinensis) x P. trifoliata e indistinguíveis até por marcadores moleculares (COLLETA et al., 2004).

Possivelmente, a elevada heterozigose existente nos citros pode ser o fator responsável pelos valores discrepantes, apresentados por descendentes de mesmos parentais, com relação à resistência a $P$. parasitica. Broadbent \& Gollnow (1994), citando Hutchison (1985), relatam que a resistência à gomose de Phytophthora é controlada por diversos genes, o que explica a diversidade de resistência de híbridos de mesmos parentais. Esses autores verificaram que citrandarins de mesmos parentais (Scarlet x Trifoliata) apresentavam valores antagônicos de resistência à gomose de Phytophthora citrophthora.

BOAVA et al. (2003), utilizando o mesmo método de inoculação, não constataram diferenças significativas entre híbridos de trifoliata de mesmos parentais quanto à resistência à gomose de $P$. parasitica. As divergências entre os resultados podem estar na forma como os autores avaliaram os danos causados pelo patógeno, uma vez que utilizaram a altura da lesão e não a porcentagem da área lesionada, bem como na virulência da estirpe, que foi a LRS 23/97, e também no estado nutricional das plântulas.

CARVALHO (2000) relata que híbridos de tangerina Sunki e $P$. trifoliata e seus recíprocos foram os mais promissores para resistência à $P$. parasítica, o que não foi confirmado no presente trabalho, visto que o citrandarin Sunki x English esteve entre os porta-enxertos com maior porcentagem de área lesionada.

\section{CONCLUSÕES}

1. O citrandarin Sunki x English (1.628), sem diferir estatisticamente dos citrandarins Cleópatra x Rubidoux (1.660), Cleópatra x English (710), Cleopatra x Swingle (715) e do trangpur Cravo x Carrizo (717), induziu a maior produção de frutos à laranjeira-Valência nas cinco primeiras colheitas do experimento, sendo que os três primeiros porta-enxertos foram os mais produtivos nas três últimas colheitas.

2. As laranjeiras-Valência enxertadas no citrandarin Cleópatra x Rubidoux (1.660) foram, em cada ano, mais produtivas que as enxertadas em seu homônimo (1.600), exceto em 1995.

3. O citrandarin Cleópatra $x$ Swingle (715), embora não diferindo de seus irmãos-germanos 1.587 e 1.614, proporcionou produções superiores a estes.

4. Os citranges Troyer e Carrizo foram significativamente inferiores aos citrandarins Sunki x English (1.628), Cleópatra x Rubidoux 
(1.660) e Cleópatra x English (710) em todos os anos, exceto em 1994.

5. Não foram constatadas diferenças significativas entre os citranges em nenhum dos anos.

6. Foram constatadas diferenças entre os porta-enxertos quanto à área lesionada pela inoculação com $P$. parasitica. Os híbridos Cleópatra x Swingle (1.587), Cleópatra x Trifoliata (1.574), Cleópatra x Rubidoux (1.600), Cravo x Carrizo (717) e Clementina x Trifoliata (1.615) foram significativamente mais resistentes que os citrandarins Cleópatra $\mathrm{x}$ Christian (712), Sunki x English (1.628), Cleópatra x Swingle (715) e Cleópatra x English (710).

7. Nenhuma das plantas apresentou sintomas de intolerância à tristeza e ao declínio dos citros.

8. Os porta-enxertos mais produtivos foram, de modo geral, mais suscetíveis à gomose de $P$. parasitica.

9. Irmãos-germanos divergiram na resistência à infecção com P. parasitica.

\section{AGRADECIMENTOS}

À Fazendas Reunidas Raio de Sol, pela cessão da área e manutenção do experimento, e ao Fundecitrus, pelo empréstimo de veículo.

Aos pesquisadores Eduardo Feichtenberger, pela cessão, e Rafael Pio, pela seleção do isolado LRS 95/03.

\section{REFERÊNCIAS}

BOAVA, L.P.; SIVIERO,A.; MASUDA, Y.; FURTADO, E.L.; MACHADO, M.A. Resistência de citrandarins e citranges a Phytophthora parasitica. Laranja, Cordeirópolis, v.24, n.1, p.135-144, 2003.

BRIDGES, G.D.; YOUTSEY, C.O. Further studies of the bud-union abnormality of rough lemon rootstocks with sweet orange scions. In: CONFERENCE OF THE INTERNATIONAL ORGANIZATION OF CITRUS VIROLOGISTS, 4., 1966. Proceedings... Gainesville: International Organization of Citrus Virologists, 1968. p.236-239.

BROADBENT, P.; GOLLNOW, B.I. Selecting disease-tolerant citrus rootstocks for Australia. In: INTERNATIONAL CITRUS CONGRESS, 1992, Acireale. Proceedings.... Acireale: International Society of Citriculture, 1994. v.2, 1994. p.758-764.
CARVALHO, M.L.T. Reação de porta-enxertos híbridos de citros à infecção de tronco e raízes por Phytophthora parasitica. 2000.87 f. Tese (Doutorado em Genética e Melhoramento) - Universidade Estadual de Campinas, Campinas, 2000.

CHIACCHIO, F.P.B.; GALLI, F. Influência da copa e do vigor das plantas cítricas sobre o comportamento do porta-enxerto em relação à Phytophthora parasitica Dastur e Phytophthora citrophthora (SM \& SM) Leonian. Revista Brasileira de Fruticultura, Cruz das Almas, v.1, n.3, p.35-45,1978.

COLLETA FILHO, H.D.; POMPEU JÚNIOR, J.; MACHADO, M.A. Certificação genética de porta-enxertos de citros: dados de 2003. Laranja, Cordeirópolis, v.25, n.1, p.171-178, 2004.

FEICHTENBERGER, E. Doenças incitadas por Phytophthora em citros. In: LUZ, E.D.M.N; MATSUOKA, K.; SANTOS, A.F. (Ed.). Doenças causadas por Phytophthora no Brasil. Campinas: Livraria Rural, 2001. p.283-342.

POMPEU JÚNIOR, J. Rootstocks and scions in the citriculture of the São Paulo State. In: CONGRESS OF THE INTERNATIONAL SOCIETY OF CITRUS NURSERYMEN, 6., 2001, Ribeirão Preto, SP. Proceedings... Bebedouro: EECB, 2001.p. 75-82.

POMPEU JÚNIOR, J.; LARANJEIRA, F.F.; BLUMER, S. Laranjeiras Valência enxertadas em hibridos de trifoliata. Scientia Agricola, Piracicaba, v.59, p.93-97, 2002a.

POMPEU JÚNIOR, J.; BLUMER, S.; LARANJEIRA, F.F. Novos híbridos de trifoliata para a citricultura paulista. Laranja, Cordeirópolis, v.23, n.2, p.413-425, 2002b.

POMPEU JÚNIOR, J.; SALVA, R; BLUMER, S. Copas e porta-enxertos nos viveiros de mudas cítricas do Estado de São Paulo. Laranja, Cordeirópolis, v.25, n.2, 2004. (no prelo)

SIVIERO, A. Métodos de inoculação da Phytophthora parasiítica e mapeamento de QTLs de resistência em híbridos de Citrus sunki vs. Poncirus trifoliata à gomose. 2001. $117 \mathrm{f}$. Tese (Doutorado) Faculdade de Ciências Agrárias, Universidade Estadual Paulista, Botucatu, 2001. 